\title{
Characterization of Precipitate Phases in a NiCoAlFeCrTi High Entropy Alloy by Transmission Electron Microscopy.
}

C.D. Gómez-Esparza ${ }^{1, *}$, F.J. Baldenebro-Lopez ${ }^{1,2}$, J.A. Baldenebro-Lopez ${ }^{2}$, R. Corral-Higuera ${ }^{2}$, J. M. Herrera-Ramírez ${ }^{1}$ and R. Martínez-Sánchez ${ }^{1}$

1. Centro de Investigación en Materiales Avanzados (CIMAV), Laboratorio Nacional de Nanotecnología, Miguel de Cervantes 120, 31109 Chihuahua, Chih., México.

2. Facultad de Ingeniería Mochis, Universidad Autónoma de Sinaloa, Prol. Ángel Flores y Fuente de Poseidón S.N., 81223 Los Mochis, Sinaloa, México.

High entropy alloys (HEA) have appeared as an important and new kind of metallic materials in the last one decade with great potential in both basic scientific knowledge and applications due to the their superior properties. It is known that chemical composition has a significant effect on the microstructure of these alloys, and it is important to investigate the influence of microstructure on the mechanical behavior.

In previous investigations, results of the microstructural and mechanical characterization of a NiCoAlFeCrTi high entropy alloy produced by mechanical alloying and conventional sintering by scanning electron microscopy, X-ray diffraction and microhardness were reported [1]. The superior hardness of this alloy in comparison to other similar high entropy alloys was attributed to the formation of nanosized Ti-rich phase. However, it was interesting to note a wide range of microhardness values, hence nanoindentation test was performed to avoid the effect of porosity on the microhardness test. The results were not different and a wide variation of nanohardness values was obtained. It was suggested that these variations in microhardness were not only due to the typical porosity of sintered products but also to the significant variations of chemical composition of phases and the presence of different precipitate phases. Therefore, microstructural observations by transmission electron microscopy were performed to characterize the sub-micron and nanosized precipitate phases.

Besides the formation of Ti-rich phase described in the previous work [1], the microstructure of the sintered NiCoAlFeCrTi high entropy alloy exhibits the formation of different precipitate phases. Fig. 1 shows TEM elemental mapping of equiaxial sub-micron dark precipitates. In Fig. 2, an overlay of elemental mapping gives evidence about the formation of Ti-rich and Al-rich precipitates. Fig. 3 presents a TEM close-up of bright needle-like precipitates and their chemical composition (Cr-Fe-rich) determined by EDS analysis.

References:

[1] C.D. Gómez-Esparza et al, Microsc. Microanal. 18, Suppl 2 (2012) p. 1920. 

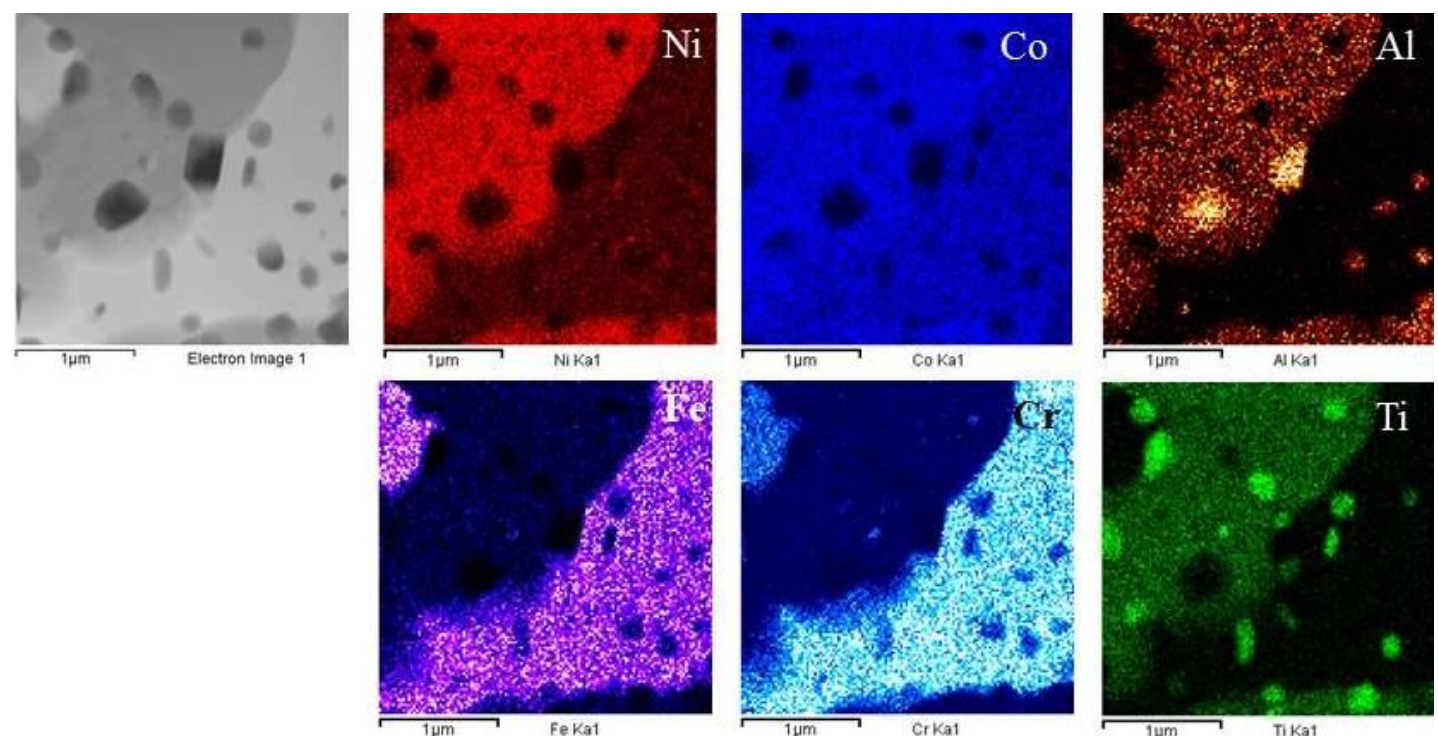

Figure 1. Elemental mapping by STEM-TEM of the NiCoAlFeCrTi alloy.

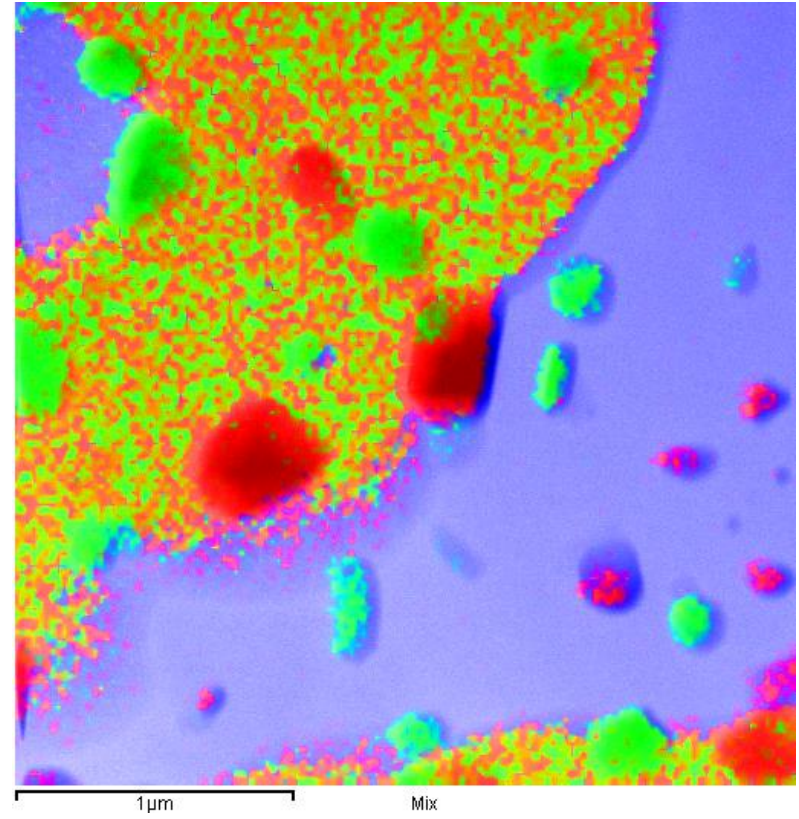

Figure 2. An overlay of the $\mathrm{Ti}$ (red), $\mathrm{Al}$ (green) and $\mathrm{Cr}$ (blue) elemental mapping on the TEM image showing the presence of two different equiaxial precipitates.

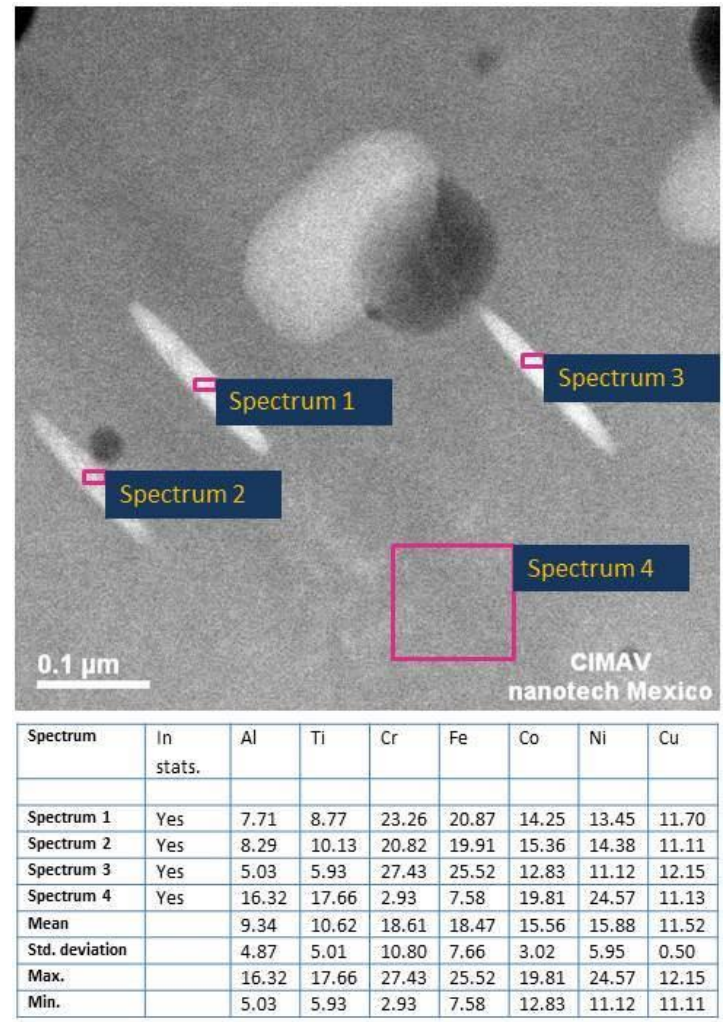

Figure 3. TEM image and EDS results showing the presence and chemical composition of bright needle-like precipitates. 